\title{
The pathologic response of resected synovial sarcomas to hyperthermic isolated limb perfusion with melphalan and TNF-a: a comparison with the whole group of resected soft tissue sarcomas
}

Benjamin Schwindenhammer ${ }^{1}$, Lars Erik Podleska², Andrea Kutritz ${ }^{1}$, Sebastian Bauer ${ }^{3}$, Sien-Yi Sheu', Georg Taeger², Kurt Werner Schmid ${ }^{1}$ and Florian Grabellus ${ }^{{ }^{*}}$

\begin{abstract}
Background: Hyperthermic isolated limb perfusion with tumor necrosis factor-a and melphalan (TM-HILP) has been successfully used to treat limb soft tissue sarcomas (STSs) with high response rates. The data on the effectiveness of HILP-TM for the treatment of STSs are mainly based on various STS types. The aim of this study was to investigate the responses of synovial sarcomas (SS) to TM-HILP.

Methods: A total of 125 TM-HILP-treated tumors (STS ${ }^{\text {all }}$ ), including 14 SSs, were included in the study. The tumors were subdivided into proximal and distal limb localizations. Tumor typing (using the WHO classification), resection status (using the UICC classification), and response to therapy were assessed using light microscopy. The SSs were tested for the SYT-SSX translocation using RT-PCR. The following tests were applied: a chi-squared test, a $t$ test, and the Mann-Whitney $U$ test.
\end{abstract}

Results: The SSs were localized distally more often than were the STS cohort (STS $\left.{ }^{-S S}\right)(85.7 \%$ vs. 32.4\%) and were smaller $(5.8 \mathrm{~cm}$ vs. $10.7 \mathrm{~cm})$. There were no differences in the responder/nonresponder ratios or the mean percentages of pathological regression between the SS and STS ${ }^{-S S}$ cohorts (74.0\% vs. $\left.76.0 \%\right)$. A general localizationdependent difference in the tumor responses to TM-HILP could not be detected in the STS ${ }^{\text {all }}$ cohort (distal, $72.0 \%$ vs. proximal, 78.0\%); however, a UICC RO status was more often observed in proximal tumors (distal, 50.0\% vs. proximal, 71.4\%). There was no association between the SYT-SSX type and SS responses to TM-HILP.

Conclusions: Because of the high response rates, TM-HILP is recommended for the treatment of SSs. The distal limb localization of TM-HILP-treated STSs was generally (STS ${ }^{\text {all }}$ cohort) associated with fewer R0 resections.

Keywords: Isolated limb perfusion, Soft tissue sarcomas, Synovial sarcomas, Tumor regression, Tumor response

\section{Background}

Soft tissue sarcomas (STSs) are members of a heterogeneous group of tumors that encompasses more than 50 subtypes. The majority of STSs are located in the limbs. The mainstay of local treatment for sarcomas of the extremities is limb-sparing surgery with complete tumor resection and clear surgical margins [1].

\footnotetext{
* Correspondence: florian.grabellus@uk-essen.de

'Institute of Pathology and Neuropathology, University Hospital of Essen and Sarcoma Center at the West German Cancer Center (WTZ), University of Duisburg-Essen, Hufelandstrasse 55, 45122, Essen, Germany

Full list of author information is available at the end of the article
}

Hyperthermic isolated limb perfusion with tumor necrosis factor- $\alpha$ (TNF- $\alpha$ ) and melphalan (TM-HILP) is a promising local treatment for locally advanced STSs, such as nonresectable STSs of the limbs, and has resulted in high tumor response rates and high limb salvage rates [2].

STSs represent a heterogeneous group of malignancies with different tumor biology and prognoses; however, the pathological grading, clinical evaluation and treatment of STS types follow common principles. Published data on the effectiveness and outcomes of TM-HILP -treated STSs are based on mixed STS cohorts:

\section{() Bïomed Central}


undifferentiated sarcomas and liposarcoma subtypes represent the majority of cases. In these studies, only sporadic histopathological regression data were obtained after TM-HILP, and the SS regression results are presented for only small numbers of cases and with variable results (Table 1 ).

The aim of this study was to investigate the STS subgroup of synovial sarcomas (SSs) and their histopathological responses to TM-HILP and to compare the results with those for the complete TM-HILP -treated STS cohort $\left(\mathrm{STS}^{-\mathrm{SS}}\right)$ and with those found in the literature.

\section{Methods}

\section{Patients}

From February 2002 to November 2012, 164 patients with STSs (including 20 with SS) were treated with TMHILP at the University Hospital of Essen.

Resection specimens could be obtained from 125 (76.2\%) patients (STS ${ }^{\text {all }}$ ), including 14 patients with SSs, for whom TM-HILP was performed to treat a nonresectable soft tissue sarcoma manifestation.

Patients were selected for the TM-HILP program according to the inclusion criteria outlined by Eggermont et al. [21]. Patient evaluation and TM-HILP treatment were exclusively performed by the same specialized team. In brief, TM-HILP was performed under mild

Table 1 Regression of SSs in other isolated limb perfusion studies with complete histopathological regression data

\begin{tabular}{|c|c|c|c|}
\hline Study & $N$ & Result (regression \%) & Valuation \\
\hline [3] & 24 & Not specified for SS & - \\
\hline$[4]$ & 24 & Not specified for SS & - \\
\hline$[5]$ & 14 & Not specified for SS & - \\
\hline$[6]$ & 10 & Not specified for SS & - \\
\hline$[7]$ & 9 & Not specified for SS & - \\
\hline$[8]$ & 6 & Not specified for SS & - \\
\hline$[9]$ & 6 & Mean 66\%; median 75\% & Modest \\
\hline$[10]$ & 5 & $2 \times>90 \% ; 3 \times 90 \%$ to $60 \%$ & Modest \\
\hline [11] & 5 & $2 \times 80 \%, 1 \times 10,35,70 \%$ & Modest \\
\hline$[12]$ & 4 & $3 \times>90 \% ; 1 \times 10$ to $50 \%$ & Good \\
\hline [13] and [14] & 4 & $3 \times \geq 50 \% ; 1 \times<50 \%$ & Modest \\
\hline$[15]$ & 4 & $3 \times 0 \% ; 1 \times 25 \%$ & Poor \\
\hline$[16]$ & 4 & $3 \times \leq 50 \% ; 1 \times>50 \%$ & Poor \\
\hline [17] & 2 & $1 \times 100 \%, 1 \times>80 \%$ & Good \\
\hline$[18]$ & 2 & $1 \times 80 \% ; 1 \times 95 \%$ & Good \\
\hline [19] & 2 & Not specified for SS & - \\
\hline$[20]^{a}$ & 1 & $1 \times>50 \%$ & - \\
\hline
\end{tabular}

Studies with complete histopathological regression data or a report of SS regression were included; ${ }^{\mathrm{T}} \mathrm{TM}-\mathrm{HILP}+$ interferon- $\gamma$. hyperthermia $\left(39^{\circ} \mathrm{C}\right)$ and leakage monitoring with radiolabeled serum. The administered dose of recombinant human TNF- $\alpha$ was adjusted to $0.25 \mathrm{mg} / \mathrm{l}$ perfused tissue volume (but not less than $1 \mathrm{mg} / \mathrm{limb}$ ), and melphalan (L-phenylalanine mustard) was used at concentrations of $11 \mathrm{mg} / \mathrm{l}$ for legs and $13 \mathrm{mg} / \mathrm{l}$ for arms.

All the patients provided informed consent, and the study was performed strictly according to the Declaration of Helsinki.

\section{Gross pathology}

All the specimens were fixated in $4 \%$ neutral buffered formalin. For all the specimens, a gross estimation of tumor necrosis was recorded and a minimum of one block per centimeter of the largest dimension of the tumor was collected.

\section{Histopathology}

Basic microscopic evaluation of H\&E-stained slides was performed.

\section{Typing and grading}

The STSs were typed according to the World Health Organization (WHO) classification of tumors for STSs and bone tumors. The STSs were graded using primary biopsies according to the French Fédération nationale des centres de lutte contre le cancer. During subtyping, the SSs were further divided into spindle cell (monophasic fibrous), biphasic, and poorly differentiated types [22].

\section{Tumor regression after therapy}

Total regression was assessed using light microscopy (Figure 1) and was determined as the percentage of the devitalized tumor after TM-HILP. Tumor regression was graded using the six-stage grading scale of SalzerKuntschik [23], and the tumors were further subdivided into 'responders' $(<10 \%$ viable tumor $)$ and 'nonresponders' ( $\geq 10 \%$ viable tumor).

\section{Reverse transcriptase polymerase chain reaction (RT-PCR)}

For RT-PCR, three or four $10-\mu \mathrm{m}$ thick sections of tumor tissue were transferred to microcentrifuge tubes and deparaffinized. RNA extraction was conducted using the RNeasy FFPE kit (QIAGEN, Hilden, Germany). For complementary deoxyribonucleic acid (cDNA) synthesis, RTPCR was performed using M-MulV reverse transcriptase (Fermentas, St Leon-Rot, Germany). The presence of amplifiable mRNA was confirmed by RT-PCR using control primer sets for hypoxanthine-phosphoribosyl-transferase. The cDNA products were then subjected to gene fusion experiments by PCR (Primers SYT-F: AGACCAA CACAGCCTGGACCA; SSX1-R: GGTGCAGTTGTTTC CCATCG; and SSX2-R: GGCACAGCTCTTTCCCATCA 

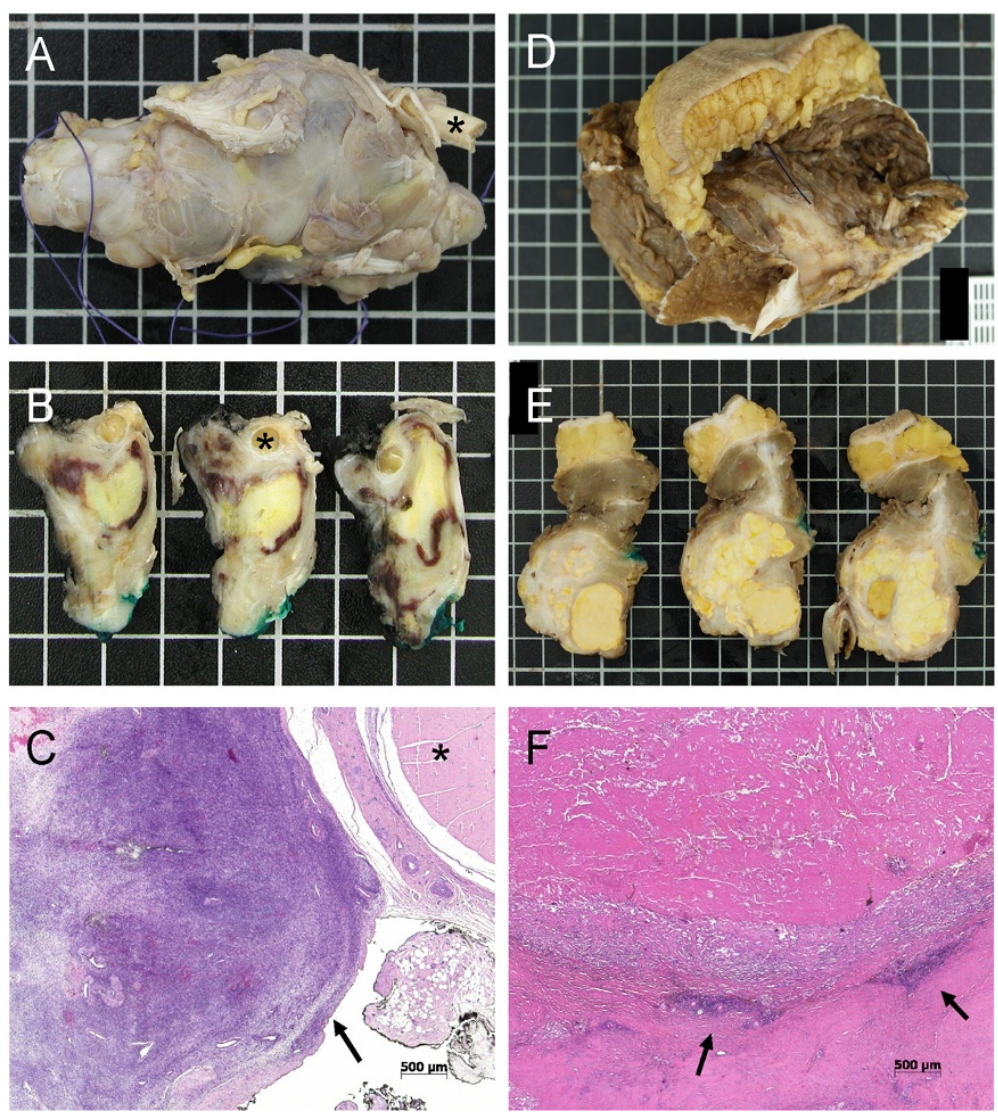

Figure 1 Macroscopic and microscopic features of two SSs after treatment with TM-HILP. (A-C) Case number 5, nonresponder. (A) $7.9 \mathrm{~cm}$ SS of the foot with a regression of 65\% after TM-HILP. (B) Necrotic areas with yellow tumor changes and viable tumor residues in proximity to a removed tendon segment $\left(^{*}\right)$. (C) Histopathology of a predominately viable tumor next to the cross-section of a tendon $\left(^{*}\right)$. The tumor infiltrates the inked margin (arrow). (D-F) Case Number 6, responder. (D) $9.0 \mathrm{~cm}$ SS of the lower leg with a regression of 99\%. (E) Abundant areas of yellow necrosis mixed with glassy-white sclerotic areas after therapy. (F) Histopathology revealed only a few small foci of viable tumor (arrows). These residues were completely removed.

[24]. Finally, the PCR products were visualized using electrophoresis with $2 \%$ agarose gels and ethidium bromide staining. The DNA from SYT-SSX1- and SYT-SSX2-positive SSs served as positive controls.

\section{Statistics}

Statistical analyses were performed with IBM SPSS Statistics 19. The following tests were applied: a chisquared test, a $t$ test, and the Mann-Whitney $U$ test. $P$ values $\leq 0.05$ were considered statistically significant.

\section{Results}

Patients

The male-to-female ratios were $6: 8$ for the synovial sarcoma (SS, Table 2) cohort and 52:59 for the complete STS cohort $\left(\mathrm{STS}^{-\mathrm{SS}}\right)$. The mean age of the SS patients was lower than that of the STS ${ }^{-S S}$ patients (45 vs. 57 years; $t$ test, $P<0.01$ ). The SSs were mainly primary tumors $(8 / 14,57.1 \%)$. Five tumors were recurrences, and one tumor was a residuum after prior surgery $\left(\mathrm{STS}^{-\mathrm{SS}}\right.$ :
86 primary tumors, $77.5 \%$; 22 recurrences, $19.8 \%$; and 3 residua, 2.7\%). Moreover, the tumors in the SS cohort were more often localized distally (proximal/distal: SS, 2/12, 85.7\% vs. STS ${ }^{-S S}, 75 / 36,32.4 \%$; chi-squared test, $P<0.001)$. Distal localization was defined distally relative to the knee or elbow joint. The foot was the primary localization of the SS cohort $(5 / 14,35.7 \%)$, and the thigh was the most frequent site of the STS ${ }^{-S S}$ cohort (60/111, $54.1 \%)$.

\section{Pathology \\ Basic parameters}

The most frequent STS subtypes of the STS ${ }^{-S S}$ cohort were the undifferentiated pleomorphic sarcoma (28/111, $25.2 \%$ ) and liposarcoma types (23/111, 20.7\%). The tumor grades according to the French Fédération nationale des centres de lutte contre le cancer (three grades: 1, 2, and 3) were 0,8 , and 6 for the SS cohort and 7,49 , and 55 for the STS ${ }^{-S S}$ cohort. Moreover, the SSs were significantly smaller at the time of resection 
Table 2 Characteristics of the synovial sarcomas

\begin{tabular}{|c|c|c|c|c|c|c|c|}
\hline Tumor number & Age of patient & Sex of patient & SS type & SYT-SSX fusion type & Localization & Size $(\mathrm{cm})$ & Regression (\%) \\
\hline 1 & 52 & Female & Spindle cell & SSX2 & Foot & 3.5 & 99 \\
\hline 2 & 44 & Male & Spindle cell & $S S X 1$ & Forearm & 3.2 & 3 \\
\hline 3 & 24 & Female & Spindle cell & $5 S \times 2$ & Lower leg & 2.5 & 85 \\
\hline 4 & 24 & Male & Spindle cell & SSX1 & Thigh & 6.2 & 98 \\
\hline 5 & 75 & Female & Biphasic & $S S X 1$ & Foot & 7.9 & 65 \\
\hline 6 & 29 & Female & Biphasic & SSX2 & Lower leg & 9.0 & 99 \\
\hline 7 & 38 & Female & Spindle cell & $S S X 1$ & Thigh & 16.0 & 20 \\
\hline 8 & 65 & Male & Spindle cell & SSX1 & Foot & 5.5 & 80 \\
\hline 9 & 70 & Female & Biphasic & SSX1 & Forearm & 3.5 & 100 \\
\hline 10 & 46 & Male & Spindle cell & SSX1 & Lower leg & 7.0 & 30 \\
\hline 11 & 10 & Female & Poorly differentiated & Wild type & Foot & 4.0 & 100 \\
\hline 12 & 45 & Male & Biphasic & $S S X 1$ & Lower leg & 10.0 & 65 \\
\hline 13 & 58 & Male & Spindle cell & SSX1 & Foot & 3.0 & 99 \\
\hline 14 & 50 & Female & Spindle cell & $S S X 1$ & Forearm & 1.2 & 98 \\
\hline
\end{tabular}

after TM-HILP (mean size: SS, $5.8 \mathrm{~cm}$ vs. STS $^{-\mathrm{SS}}, 10.7$ cm; Mann-Whitney $U$ test, $P=0.004$ ).

\section{Regression after TM-HILP}

There were $7 / 14(50.0 \%)$ responders in the SS cohort according to the Salzer-Kuntschik regression grading scale. Two (14.3\%) of those SSs exhibited complete pathological regression. The $\mathrm{STS}^{-\mathrm{SS}}$ cohort included 66/111 (59.5\%) responders, of which 24 (21.6\%) were complete responders. There were no differences in the responder/ nonresponder ratios (chi-squared test, $P=0.499$ ) or in the mean percentages of pathological regression between the SS and STS $^{-S S}$ cohorts (SS, 74.0\% vs. STS ${ }^{-S S}, 76.0 \%$; Mann-Whitney $U$ test, $P=0.776$, Figure 2).

Because of the predominant distal localization of the SSs in this study, we did not detect any localizationdependent (distal/proximal) differences in the tumor responses to TM-HILP according to the mean percentages of pathological regression in the STS $^{\text {all }}$ cohort (distal, $N=48,72.0 \%$ vs. proximal, $N=77 ; 78.0 \%$; Mann-Whitney $U$ test, $P=0.493$ ).

\section{The SYT-SSX fusion type and responses}

Overall, ten SS cases were SYT-SSX1-positive and three were SYT-SSX2-positive. In one case (see Table 1), none of the fusions could be detected by PCR. Despite the negative molecular pathological results for SYT-SSX1 and SYT-SSX2, this tumor was typed as SS by three sarcoma experts at three different institutions because of its conventional, immunohistochemical characteristics and a borderline fluorescence in situ hybridization result.

The SSs with these genetic signatures included both responders and nonresponders (see Table 1), and there were no significant differences among the responses to
TM-HILP. The SYT-SSX2 fusion type was exclusively found in female patients $(3 / 3)$.

\section{Resectability}

The investigation of the resection status (UICC, R classification) found 8/14 (57.1\%) complete resections (R0 status) in the SS cohort. Both complete responders (100\% pathological devitalization) in the SS group had an R1 status. Complete resection was observed in $71 / 111$ (64.0\%) STS $^{-S S}$ tumors. This difference between the groups was not statistically significant (chi-squared test, $P=0.618)$. Both proximal SSs $(2 / 2)$ and $6 / 12$ of the distal SSs were completely resected, which is principally in line with the results below, but was not significant for

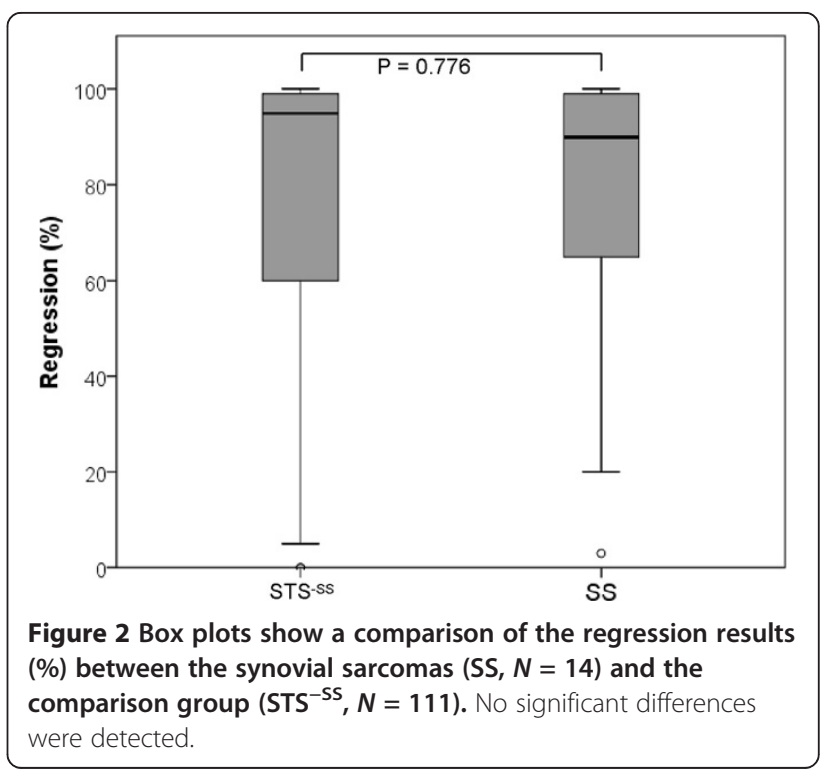


the SS group alone. However, the resection status results of the proximal and distal limb localizations indicated better resectability for proximal STSs in the $\mathrm{STS}^{-\mathrm{SS}}$ cohort according to the R0 status (53/71 R0 proximal, $74.6 \%$ vs. $22 / 40$ R0 distal, $55.0 \%$; chi-squared test, $P=0.034)$. This result remained statistically significant when the 14 SSs were included in the calculation (STS ${ }^{\text {all }}: 55 /$ $77,71.4 \%$ vs. $24 / 48,50.0 \%$; chi-squared test, $P=0.016$ ).

\section{Discussion}

The treatment of STSs is increasingly determined by the identification of histological subtypes in a family of uncommon cancers that comprises more than 50 subtypes [25]. Published data on the effectiveness and outcomes of TM-HILP-treated STSs are based on studies in which common and rare STS entities were mixed [2]. Histology is relevant for target therapies and now for the precise application of conventional chemotherapy regimens; therefore, we suggest that the effect of TM-HILP on STS subentities should be confirmed.

\section{The frequencies and sizes of the SSs}

SSs represent approximately $5 \%$ to $10 \%$ of all STSs. Because of their predominant localization within the limbs, the frequency of SSs at limb sites has ranged from 12\% to $15 \%$ of all limb STSs [26]. The frequency of SSs in this investigation was $11.2 \%$ in a limb STS cohort, which is within the range of previously published data. Additionally, we observed a smaller median tumor size (4.2 $\mathrm{cm})$ than that reported for large SS cohorts $(6$ to $7 \mathrm{~cm}$ ) [27-30]. This finding may be a consequence of the various tumors in this study, which included primary tumors $(5.5 \mathrm{~cm})$ and recurrences and residual tumors after surgery $(3.7 \mathrm{~cm})$.

\section{Localization of the SSs}

Most SSs are limb-based tumors. Approximately 67\% to $86 \%$ of SSs arise within the extremities [27-31]. Of those SSs, distal localization was found in $47 \%$ to $71 \%$ $[27,29,31]$ of cases, which is approximately twice as high as the rates for limb STSs [32,33]. Additionally, a higher rate was found in this study (86.7\%), which is a hallmark of isolated limb perfusion (ILP) studies.

\section{Responses of SSs to TM-HILP}

The clinical and pathological response rates of sarcomas to TM-HILP are typically high. The mean clinical overall response in TM-HILP studies according to the WHO criteria [34] was initially reported to be more than $90 \%$ with complete responses in more than $80 \%$ of cases [35]. To date, the largest studies have adjusted these clinical data downward to an overall response rate of approximately $70 \%$ and a complete response rate of $20 \%$ [36]. Interestingly, clinical and pathological response evaluations have often differed substantially, which we have recently demonstrated to be the result of an insufficiency in sizebased clinical response criteria that would indicate actual tumor responses (measured by a pathological investigation as the gold standard) [37]. The SS cohort exhibited a mean pathological response rate that was approximately identical to that of the STS ${ }^{-S S}$ in this cohort of resected STS. This indicates that TM-HILP can be recommended for this STS subtype despite the disproportionate number of distal limb localizations.

\section{Responses of the genetic subtypes to TM-HILP}

The $\mathrm{t}(\mathrm{X} ; 18)$ translocation, which results from the $S Y T$ SSX1 and SYT-SSX2 gene fusions, is found in approximately all SSs [26]. This genetic alteration has not yet been found in any other human malignancy; therefore, these genetic signatures have significant diagnostic value. The impact of the SYT-SSX fusion type on the clinical behavior of SSs is the subject of scholarly discourse with contrasting results $[28,38]$. The influence of the translocation type on the response to treatment has not been investigated to date but might be reflected by the prognostic significance of the type according to metastatic potential and overall survival times [38,39]. This study did not find varying responses to TM-HILP among the SYT-SSX translocation types in our small SS cohort.

\section{Resectability of the SSs after TM-HILP}

The mainstay of surgical treatment for STSs is limbsparing resection with clear surgical margins [1]. There is disagreement regarding the size of an adequate wide surgical margin [1]. TM-HILP is indicated only for the subgroup of STS patients who are candidates for disabling surgery or amputation. In this study, a surgical approach with oncological adequacy of margin width was not possible. Even after TM-HILP, the margin size and quality is generally poor [40]. However, we have previously demonstrated that local tumor control after TM-HILP and resection is superior compared with nonpretreated STSs, most probably due to the strong toxic effects of TM-HILP on the tumor periphery $[3,40]$.

This study demonstrated a high rate of distally located tumors (40\%), which is typical for ILP-treated STS cohorts compared with most non-ILP-treated cohorts. Because of the specific anatomic conditions that are found in the distal parts of the extremities, the rate of complete resections with clear surgical margins is generally low [41]. Tumors are frequently rated as 'primarily unresectable' and are possible candidates for TM-HILP programs. Several large studies have demonstrated proximal and distal localizations of STSs but only provided the histological margin status for the complete cohort $(\approx 10 \%$ to $20 \%$ R1-resections) [33,42,43]. Studies that have selectively investigated 'distal STSs' have not 
included histopathological data concerning the surgical margins [44-48].

This study found a comparatively high rate of incompletely resected tumors after TM-HILP (38.4\%), which is in agreement with results from studies in Rotterdam $[15,36]$. In addition, this study found a significantly reduced resectability (in terms of the R0 classification) rate in distal limb localizations [15]. Interestingly, the average width of the margins of the R0 resected tumors did not vary significantly according to localization and was low: the proximal mean was $0.8 \mathrm{~mm}$, and the distal mean was $1.2 \mathrm{~mm}$.

A worsening of the effectiveness of TM-HILP on distally located STSs, possibly due to impaired blood flow, was not detected in our study. Deroose et al. [15] recently investigated STSs of distal limbs and found a limb salvage rate of $87 \%$ after TM-HILP. They stated, 'TMILP is an effective treatment modality in patients with distal STS,' but they found a considerably lower average percentage of pathological regression than that in this study (33.4\% vs. $70.0 \%)$.

\section{Conclusion}

In conclusion, we found that the preoperative treatment TM-HILP is as effective for the subentity of SSs as for the complete group of STSs. Accordingly, TMHILP is recommended for this tumor type even though it is often located distally. A distal localization resulted in reduced resectability in the STS ${ }^{\text {all }}$ cohort according to the R0 rate, but the margin size of the complete resections did not differ significantly between both types of localization.

\footnotetext{
Abbreviations

$H$ \& E: hematoxylin and eosin; ILP: isolated limb perfusion; RT-PCR: reverse transcriptase polymerase chain reaction; SS: synovial sarcomas or cohort of SS of this study; STS: soft tissue sarcomas; STS all: all soft tissue sarcomas of the present study (SS included); STS ${ }^{-S S}$ : soft tissue sarcomas of the present study, excluding SS (comparison group); TM-HILP: hyperthermic isolated limb perfusion with TNF-a and melphalan; TNF-a: tumor necrosis factor-a; UICC: Union for International Cancer Control; WHO: World Health Organization.
}

\section{Competing interests}

The authors declare that they have no competing interests.

\section{Authors' contributions}

BS, LEP, AK, GT and FG made substantial contributions to conception and design, or acquisition of data, or analysis and interpretation of data. BS was responsible for histopathology. LEP and GT were responsible for the clinical data. AK was responsible for genetic testing. FG was responsible for histopathology and statistics. BS, LEP, SS and FG were involved in drafting the manuscript or revising it for important intellectual content. BS and KWS designed the study and drafted the manuscript. All authors read and approved the final manuscript.

\section{Author details}

${ }^{1}$ Institute of Pathology and Neuropathology, University Hospital of Essen and Sarcoma Center at the West German Cancer Center (WTZ), University of Duisburg-Essen, Hufelandstrasse 55, 45122, Essen, Germany. ${ }^{2}$ Department of Trauma Surgery (Musculoskeletal Surgical Oncology), University Hospital of
Essen and Sarcoma Center at the West German Cancer Center (WTZ), University of Duisburg-Essen, Essen, Germany. ${ }^{3}$ Department of Internal Medicine (Cancer Research), University Hospital of Essen and Sarcoma Center at the West German Cancer Center (WTZ), University of Duisburg-Essen, Essen, Germany.

Received: 25 February 2013 Accepted: 5 August 2013

Published: 12 August 2013

\section{References}

1. The ESMO / European Sarcoma Network Working Group: Soft tissue and visceral sarcomas: ESMO clinical practice guidelines for diagnosis, treatment and follow-up. Ann Oncol 2012, 23(Suppl 7):vii92-vii99.

2. Grunhagen DJ, de Wilt JH, ten Hagen TL, Eggermont AM: Technology insight: utility of TNF-a-based isolated limb perfusion to avoid amputation of irresectable tumors of the extremities. Nat Clin Pract Oncol 2006, 3:94-103.

3. Deroose JP, Burger JW, van Geel AN, den Bakker MA, de Jong JS, Eggermont AM, Verhoef C: Radiotherapy for soft tissue sarcomas after isolated limb perfusion and surgical resection: essential for local control in all patients? Ann Surg Oncol 2011, 18:321-327.

4. Muret J, Yacoub M, Terrier P, Drusch F, Laplanche A, Gaudin C, Richon C, Le Pechoux C, Le Cesne A, Lejeune FJ, Tursz T, Fouret P, Bonvalot S, Chouaib S: p53 status correlates with histopathological response in patients with soft tissue sarcomas treated using isolated limb perfusion with TNFalpha and melphalan. Ann Oncol 2008, 19:793-800.

5. Thijssens KM, van Ginkel RJ, Pras E, Suurmeijer AJ, Hoekstra HJ: Isolated limb perfusion with tumor necrosis factor $a$ and melphalan for locally advanced soft tissue sarcoma: the value of adjuvant radiotherapy. Ann Surg Oncol 2006, 13:518-524.

6. Pennacchioli E, Deraco M, Mariani L, Fiore M, Mussi C, Collini P, Olmi P, Casali PG, Santinami M, Gronchi A: Advanced extremity soft tissue sarcoma: prognostic effect of isolated limb perfusion in a series of 88 patients treated at a single institution. Ann Surg Oncol 2007, 14:553-559.

7. Kettelhack C, Wickede M, Vogl T, Schneider U, Hohenberger P: ${ }^{31}$ Phosphorus-magnetic resonance spectroscopy to assess histologic tumor response noninvasively after isolated limb perfusion for soft tissue tumors. Cancer 2002, 94:1557-1564.

8. Noorda EM, Vrouenraets BC, Nieweg OE, van Coevorden F, van Slooten GW, Kroon BB: Isolated limb perfusion with tumor necrosis factor- $a$ and melphalan for patients with unresectable soft tissue sarcoma of the extremities. Cancer 2003, 98:1483-1490.

9. Grabellus F, Kraft C, Sheu-Grabellus SY, Bauer S, Podleska LE, Lauenstein TC, Pottgen C, Konik MJ, Schmid KW, Taeger G: Tumor vascularization and histopathologic regression of soft tissue sarcomas treated with isolated limb perfusion with TNF-a and melphalan. J Surg Oncol 2011, 103:371-379.

10. Issakov J, Merimsky O, Gutman M, Kollender $Y$, Lev-Chelouche D, Abu-Abid S, Lifschitz-Mercer B, Inbar M, Klausner JM, Meller I: Hyperthermic isolated limb perfusion with tumor necrosis factor-a and melphalan in advanced soft-tissue sarcomas: histopathological considerations. Ann Surg Oncol 2000, 7:155-159.

11. Stein $U$, Jurchott $K$, Schlafke $M$, Hohenberger P: Expression of multidrug resistance genes MVP, MDR1, and MRP1 determined sequentially before, during, and after hyperthermic isolated limb perfusion of soft tissue sarcoma and melanoma patients. J Clin Oncol 2002, 20:3282-3292.

12. Olieman AF, van Ginkel RJ, Hoekstra HJ, Mooyaart EL, Molenaar WM, Koops HS: Angiographic response of locally advanced soft-tissue sarcoma following hyperthermic isolated limb perfusion with tumor necrosis factor. Ann Surg Oncol 1997, 4:64-69.

13. Plaat BE, Molenaar WM, Mastik MF, Koudstaal J, Van Den Berg E, Koops HS, Hoekstra HJ: Hyperthermic isolated limb perfusion with tumor necrosis factor- $a$ and melphalan in patients with locally advanced soft tissue sarcomas: treatment response and clinical outcome related to changes in proliferation and apoptosis. Clin Cancer Res 1999, 5:1650-1657.

14. Komdeur R, Plaat BE, Hoekstra HJ, Molenaar WM, Hollema H, Van Den Berg E, Mastik MF, van der Graaf WT: Expression of P-glycoprotein, multidrug resistance-associated protein 1 , and lung resistance-related protein in human soft tissue sarcomas before and after hyperthermic isolated limb perfusion with tumor necrosis factor-a and melphalan. Cancer 2001, 91:1940-1948. 
15. Deroose JP, van Geel AN, Burger JW, Eggermont AM, Verhoef C: Isolated limb perfusion with TNF-alpha and melphalan for distal parts of the limb in soft tissue sarcoma patients. J Surg Oncol 2012, 105:563-569.

16. van Rijswijk CS, Geirnaerdt MJ, Hogendoorn PC, Peterse JL, van Coevorden F, Taminiau AH, Tollenaar RA, Kroon BB, Bloem JL: Dynamic contrastenhanced MR imaging in monitoring response to isolated limb perfusion in high-grade soft tissue sarcoma: initial results. Eur Radiol 2003, 13:1849-1858.

17. van Ginkel RJ, Hoekstra HJ, Pruim J, Nieweg OE, Molenaar WM, Paans AM, Willemsen AT, Vaalburg W, Koops HS: FDG-PET to evaluate response to hyperthermic isolated limb perfusion for locally advanced soft-tissue sarcoma. J Nucl Med 1996, 37:984-990.

18. Been LB, Suurmeijer AJ, Elsinga PH, Jager PL, van Ginkel RJ, Hoekstra HJ: $18 \mathrm{~F}$-fluorodeoxythymidine PET for evaluating the response to hyperthermic isolated limb perfusion for locally advanced soft-tissue sarcomas. J Nucl Med 2007, 48:367-372.

19. Vanel D, Bonvalot $S$, Guinebretiere JM, Petrow $P$, Dromain C, Caillet H: MR imaging in the evaluation of isolated limb perfusion: a prospective study of 18 cases. Skeletal Radiol 2004, 33:150-156.

20. Eggermont AM, Schraffordt KH, Lienard D, Kroon BB, van Geel AN, Hoekstra $H J$, Lejeune FJ: Isolated limb perfusion with high-dose tumor necrosis factor-alpha in combination with interferon-gamma and melphalan for nonresectable extremity soft tissue sarcomas: a multicenter trial. J Clin Oncol 1996, 14:2653-2665.

21. Eggermont AM, Schraffordt KH, Klausner JM, Kroon BB, Schlag PM, Lienard D, van Geel AN, Hoekstra HJ, Meller I, Nieweg OE, Kettelhack C, Ben-Ari G, Pector JC, Lejeune FJ: Isolated limb perfusion with tumor necrosis factor and melphalan for limb salvage in 186 patients with locally advanced soft tissue extremity sarcomas. The cumulative multicenter European experience. Ann Surg 1996, 224:756-764.

22. Fletcher CDM, Unni KK, Mertens FE: World Health Organization Classification of Tumors. Pathology and Genetics of Tumors of Soft Tissue and Bone. Lyon: IARC Press; 2002

23. Salzer-Kuntschik M, Delling G, Beron G, Sigmund R: Morphological grades of regression in osteosarcoma after polychemotherapy - study COSS 80 . J Cancer Res Clin Oncol 1983, 106(Suppl):21-24.

24. Tamborini E, Agus V, Perrone F, Papini D, Romano R, Pasini B, Gronchi A, Colecchia M, Rosai J, Pierotti MA, Pilotti S: Lack of SYT-SSX fusion transcripts in malignant peripheral nerve sheath tumors on RT-PCR analysis of 34 archival cases. Lab Invest 2002, 82:609-618.

25. Casali PG: Histology- and non-histology-driven therapy for treatment of soft tissue sarcomas. Ann Oncol 2012, 23(Suppl 10):x167-x169.

26. Eilber FC, Dry SM: Diagnosis and management of synovial sarcoma. J Surg Oncol 2008, 97:314-320.

27. Deshmukh R, Mankin HJ, Singer S: Synovial sarcoma: the importance of size and location for survival. Clin Orthop Relat Res 2004, 419:155-161.

28. Guillou L, Benhattar J, Bonichon F, Gallagher G, Terrier P, Stauffer E, Somerhausen NS, Michels JJ, Jundt G, Vince DR, Taylor S, Genevay M, Collin F, Trassard M, Coindre JM: Histologic grade, but not SYT-SSX fusion type, is an important prognostic factor in patients with synovial sarcoma: a multicenter, retrospective analysis. J Clin Oncol 2004, 22:4040-4050.

29. Shi W, Indelicato DJ, Morris CG, Scarborough MT, Gibbs CP, Zlotecki RA: Long-term treatment outcomes for patients with synovial sarcoma: a 40-year experience at the University of Florida. Am J Clin Oncol 2013, 36:83-88.

30. Trassard M, Le Doussal V, Hacene K, Terrier P, Ranchere D, Guillou L, Fiche M, Collin F, Vilain MO, Bertrand G, Jacquemier J, Sastre-Garau X, Bui NB, Bonichon F, Coindre JM: Prognostic factors in localized primary synovial sarcoma: a multicenter study of 128 adult patients. J Clin Oncol 2001, 19:525-534.

31. Ferrari A, Gronchi A, Casanova M, Meazza C, Gandola L, Collini P, Lozza L, Bertulli R, Olmi P, Casali PG: Synovial sarcoma: a retrospective analysis of 271 patients of all ages treated at a single institution. Cancer 2004, 101:627-634.

32. Cormier JN, Langstein HN, Pisters PW: Preoperative therapy for soft tissue sarcoma. Cancer Treat Res 2004, 120:43-63.

33. Weitz J, Antonescu CR, Brennan MF: Localized extremity soft tissue sarcoma: improved knowledge with unchanged survival over time. J Clin Oncol 2003, 21:2719-2725.

34. Jaffe CC: Measures of response: RECIST, WHO, and new alternatives. J Clin Oncol 2006, 24:3245-3251.
35. Eggermont AM, de Wilt JH, ten Hagen TL: Current uses of isolated limb perfusion in the clinic and a model system for new strategies. Lancet Oncol 2003, 4:429-437.

36. Deroose JP, Eggermont AM, van Geel AN, Burger JW, den Bakker MA, de Wilt $J$, Verhoef $C$ : Long-term results of tumor necrosis factor a- and melphalan-based isolated limb perfusion in locally advanced extremity soft tissue sarcomas. J Clin Oncol 2011, 29:4036-4044.

37. Grabellus F, Stylianou E, Umutlu L, Sheu SY, Lehmann N, Taeger G, Lauenstein TC: Size-based clinical response evaluation is insufficient to assess clinical response of sarcomas treated with isolated limb perfusion with TNF-a and melphalan. Ann Surg Oncol 2012, 19:3375-3385.

38. Ladanyi M, Antonescu CR, Leung DH, Woodruff JM, Kawai A, Healey JH, Brennan MF, Bridge JA, Neff JR, Barr FG, Goldsmith JD, Brooks JS, Goldblum JR, Ali SZ, Shipley J, Cooper CS, Fisher C, Skytting B, Larsson O: Impact of SYT-SSX fusion type on the clinical behavior of synovial sarcoma: a multi-institutional retrospective study of 243 patients. Cancer Res 2002, 62:135-140.

39. Kawai A, Woodruff J, Healey JH, Brennan MF, Antonescu CR, Ladanyi M: SYT-SSX gene fusion as a determinant of morphology and prognosis in synovial sarcoma. N Engl J Med 1998, 338:153-160.

40. Grabellus F, Kraft C, Sheu SY, Ebeling P, Bauer S, Lendemans S, Schmid KW, Taeger $\mathrm{G}$ : Evaluation of 47 soft tissue sarcoma resection specimens after isolated limb perfusion with TNF-a and melphalan: histologically characterized improved margins correlate with absence of recurrences. Ann Surg Oncol 2009, 16:676-686

41. Ferguson PC: Surgical considerations for management of distal extremity soft tissue sarcomas. Curr Opin Oncol 2005, 17:366-369.

42. Eilber FC, Rosen G, Eckardt J, Forscher C, Nelson SD, Selch M, Dorey F, Eilber FR: Treatment-induced pathologic necrosis: a predictor of local recurrence and survival in patients receiving neoadjuvant therapy for high-grade extremity soft tissue sarcomas. J Clin Oncol 2001, 19:3203-3209.

43. Gaynor JJ, Tan CC, Casper ES, Collin CF, Friedrich C, Shiu M, Hajdu SI, Brennan MF: Refinement of clinicopathologic staging for localized soft tissue sarcoma of the extremity: a study of 423 adults. J Clin Oncol 1992 10:1317-1329.

44. Colterjohn NR, Davis AM, O'Sullivan B, Catton CN, Wunder JS, Bell RS: Functional outcome in limb-salvage surgery for soft tissue tumours of the foot and ankle. Sarcoma 1997, 1:67-74.

45. Jyothirmayi $R$, Sittampalam $Y$, Harmer $C$ : Soft tissue sarcoma of the hand or foot: conservative surgery and radiotherapy. Sarcoma 1999, 3:17-24.

46. Okunieff $P$, Suit HD, Proppe KH: Extremity preservation by combined modality treatment of sarcomas of the hand and wrist. Int J Radiat Oncol Biol Phys 1986, 12:1923-1929.

47. Talbert ML, Zagars GK, Sherman NE, Romsdahl MM: Conservative surgery and radiation therapy for soft tissue sarcoma of the wrist, hand, ankle, and foot. Cancer 1990, 66:2482-2491.

48. Zeytoonjian T, Mankin HJ, Gebhardt MC, Hornicek FJ: Distal lower extremity sarcomas: frequency of occurrence and patient survival rate. Foot Ankle Int 2004, 25:325-330

\section{doi:10.1186/1477-7819-11-185}

Cite this article as: Schwindenhammer et al:: The pathologic response of resected synovial sarcomas to hyperthermic isolated limb perfusion with melphalan and TNF-a: a comparison with the whole group of resected soft tissue sarcomas. World Journal of Surgical Oncology 2013 11:185 